\title{
The Evolving Structure of Multi-Hospital Systems in the US: Focus on California
}

\author{
Glenn Melnick, June F. o'Leary \\ Sol Price School of Public Policy, University of Southern California, Los Angeles, CA, USA \\ Email: gmelnick@usc.edu; jo_551@usc.edu
}

How to cite this paper: Melnick, G. and O'Leary, J.F. (2021) The Evolving Structure of Multi-Hospital Systems in the US: Focus on California. Health, 13, 757-765.

https://doi.org/10.4236/health.2021.137058

Received: June 27, 2021

Accepted: July 17, 2021

Published: July 20, 2021

Copyright $\odot 2021$ by author(s) and Scientific Research Publishing Inc. This work is licensed under the Creative Commons Attribution International License (CC BY 4.0).

http://creativecommons.org/licenses/by/4.0/

\begin{abstract}
Objectives: Hospital consolidation and the growth of multi-hospital systems are generating media headlines in the US. While there is a growing literature on the role of multi-hospital systems in the US health care system, it is still quite limited. This study helps fill the gap by documenting and describing the structure and evolution of multi-hospital systems in California over a recent 18-year period. Methods: Descriptive analysis of a hospital level longitudinal database covering the period 2002-2019 in California. Results: The total number of hospitals declined by 40 hospitals, from 445 to 405 , over the study period and the total number of multi-hospital systems increased substantially from 14 systems in 2002 to 30 systems in 2019. As a result, the number and proportion of all California hospitals that were part of a multi-hospital system grew-from 177 in 2002 to 238 in 2019. By 2019, 59\% of all hospitals were part of systems (compared to $40 \%$ in 2002). The size distribution of multi-hospital systems in California changed substantially over time. In the early period, larger systems dominated the system landscape. Now, half of all systems have 5 or fewer hospitals compared to $29 \%$ in 2002, while the percentage of systems with 25 or more members has declined from $25 \%$ to just $7 \%$. Interestingly, the clinical service mix of hospital systems has changed substantially. In 2002, all 14 systems were largely acute care focused. By 2019, less than half of systems had acute care as their only and primary focus. Conclusions: Combined, these findings provide insight into the development, evolution and growing role of hospitals systems in our health care system and identify new areas for further research.
\end{abstract}

\section{Keywords}

Hospital Systems, Consolidation, Multi-Hospital Systems

\section{Introduction and Background}

Hospital consolidation and the growth of multi-hospital systems are generating 
growing interest and media headlines in the US [1]. A recent report documented 680 hospital mergers over the past decade [2] and forecast more in the future [3]. Many of these mergers result in the formation or expansion of multi-hospital systems. The New York Times reported, "Hospitals across the nation are being swept up in the biggest wave of mergers since the 1990s, a development that is creating giant hospital systems that could one day dominate American health care (and drive-up costs)" [4].

The motivations and likely outcomes of this trend toward expanded multi-hospital systems are subject to debate [5] [6] [7]. The Affordable Care Act and the growth of accountable care organizations are cited as factors driving the growth of more and larger multi-hospital enterprises [8] [9] [10]. Hospitals underscore as benefits of joining multi-hospital systems the capacity to serve larger populations more efficiently by focusing on population health management to improve outcomes and reduce costs. A competing view is that by consolidating into ever larger multi-hospital systems, it becomes virtually impossible for health plans to develop insurance products without including at least some of the system's member hospitals in their preferred contracted networks-so called "must-have" hospitals. When this occurs, the multi-hospital system gains leverage to negotiate contracts with health plans on a "system-wide, all-or-none" basis, requiring the plan to include not only the "must have" hospitals but all other system member hospitals in the plan's preferred networks, regardless of their prices (or quality) relative to other potential substitutes in the market [11]. This requirement which ties all system members together for contracting purposes potentially endows system members with market power that can lead to higher prices that must be paid by commercial health plans and result in higher health insurance premiums to consumers.

While there is a growing literature on the growth and potential effects of multi-hospital systems, it is still limited. This paper provides a descriptive analysis of the development, growth, evolution, and structure of multi-hospital systems over an extended time period. The database for this paper covers all licensed general acute care hospitals in California between 2002-2019.

We find that the role and importance of multi-hospital systems have expanded substantially over time, while the service-mix and scale of multi-hospitals systems have simultaneously changed. Our study findings are potentially useful to researchers and policy makers across the country for several reasons. In particular, California experienced its wave of consolidation and multi-hospital system formation and growth much earlier than the rest of the country. As such, California's experience with hospital systems may provide insights into the future as multi-hospital systems form in the rest of the country, and also provide a basis for further research to better understand the drivers of these trends and their implications for our health care system.

\section{Data and Sample}

Study data span 2002-2019 and the sample includes all hospitals reporting data 
to the State of California as acute care hospitals. Data are provided by the California Office of Statewide Health Planning and Development (OSHPD). OSHPD collects detailed data each year from all California hospitals using a set of highly structured questions to produce standardized reports. We access the Annual Pivot Data report, which includes detailed information on hospital beds, utilization, services and whether or not the hospital is part of a multi-hospital system, and, if so, the name of the system. We supplement this hospital-specific data with Bureau of the Census estimates of population counts and data from the California Health Care Foundation on HMO enrollment trends. While our study covers all California hospitals, detailed data for hospitals that are part of Kaiser Permanente HMO (hereafter Kaiser) are limited to 2007-2019 and are included only in two Figures (Figure 1 and Figure 4). As a result, analyses covering the 2002-2019 period exclude Kaiser hospitals.

\section{Study Design and Analysis}

Our study is designed to describe and quantify the growth and changing structure of multi-hospital systems in California over an extended period. We use annual data reported by each hospital to construct time-series profiles of both independent, free standing hospitals as well as hospitals that belong to systems. The key variables of interest include: inpatient discharges (total and by service type), beds, number of hospitals and systems status-whether or not a hospital was part of a multi-hospital system and, if so, which system the hospital was part of. Since hospitals can change their system status, we constructed a time-series file (2002-2019) that includes all hospitals coded whether they were in a system in a given year and the name of the system for that year. We also constructed a service mix profile for each system for the year 2019. The profiles were based on the mix of patient days by type of service, including: hospital where their patients were concentrated in single service (acute, psychiatric, rehabilitation) or if they had a mix of services (acute + psychiatric, acute + long term care, acute + psychiatric + long term care + rehabilitation).

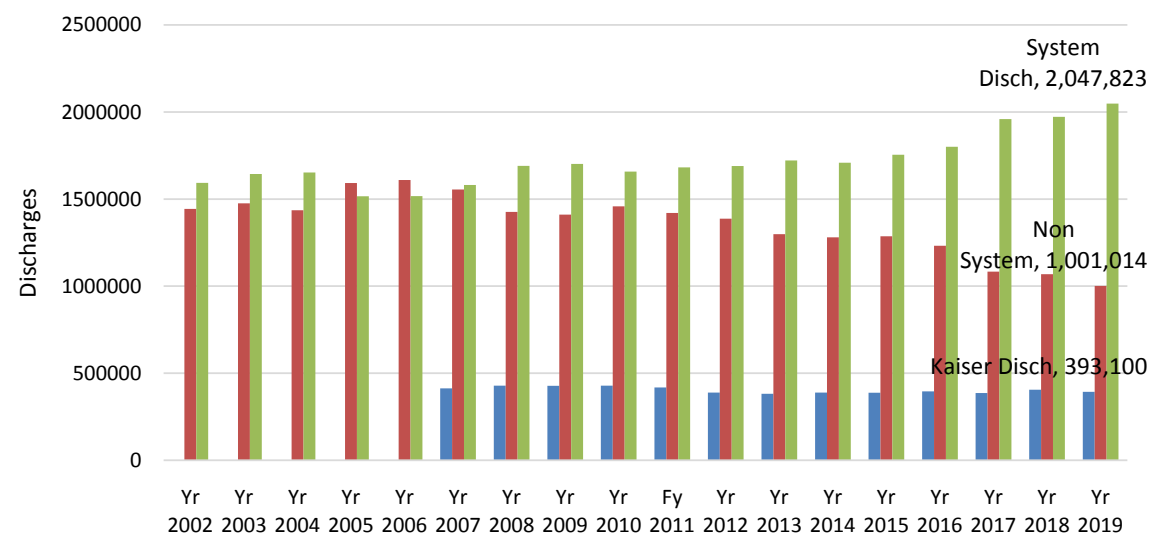

Figure 1. Hospital discharges in California: system and non-system hospitals, 2002-2019 and Kaiser System Hospitals, 2007-2019. 


\section{Results}

To provide background on the size and growth of the hospital market in California Figure 1 presents data on hospital discharges in California by system status over the study period. Total discharges combined for system plus non-system hospitals (excluding Kaiser) are relatively unchanged when comparing 2002 and 2019 (approximately 3.04 million discharges both years). However, the distribution of discharges between system and non-system hospitals changed substantially over the period. In 2002, discharges were almost equally split between system and non-system hospitals, but by 2019, system hospitals totaled 2.047 million discharges while non-system hospitals totaled 1.001 million discharges. The trend data for Kaiser, covering 2007-2019, show a slightly different pattern. Discharges from Kaiser hospitals declined from 0.413 million in 2007 to 0.393 million in $2019(-5 \%)$. Overall, total discharges across all hospitals, system and non-system and Kaiser totaled 3.441 million in 2019 compared to 3.549 in 2007, a $-3 \%$ reduction. Interestingly, while total hospital discharges in California showed a downward trend, the total population in California grew by $14 \%$ between 2002 and 2019 and by $9 \%$ between 2007 and 2019.

Figure 2 shows trend data regarding total number of hospitals, the distribution of hospitals by system status and the number of multi-hospital systems over time. The total number of hospitals declined by 40 hospitals, from 445 to 405 , over the study period. Some of these hospitals may have closed outright and their capacity removed from the market or their capacity may have been absorbed by either independent hospitals or multi-hospital systems. The total number of multi-hospital systems increased substantially, more than doubling, from 14

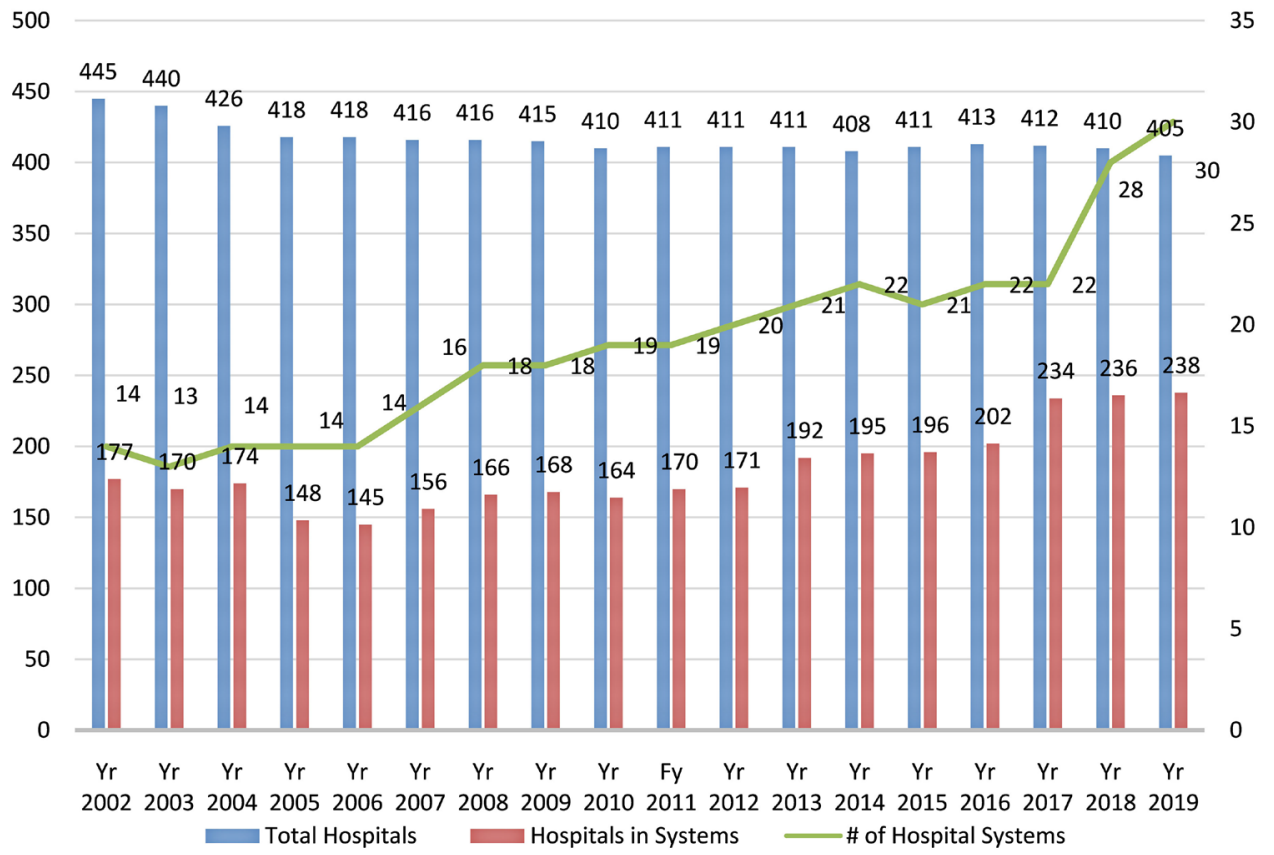

Figure 2. Number of multi-hospital systems and distribution of hospitals by system status (excluding Kaiser system hospitals), California, 2002-2019. 
systems in 2002 to 30 systems in 2019. Along with the growth of the number of hospital systems is the growth in the number and proportion of all California hospitals in systems-from 177 in 2002 to 238 in 2019. By 2019, 59\% of all hospitals were part of systems (compared to $40 \%$ in 2002).

Figure 3 shows trend data regarding the supply of hospital beds by system status and the percent of total beds in multi-hospital systems over time. The total number of hospital beds in all California hospitals declined from 96,313 to 88,896 ( -7345 beds or $-8 \%$ ) over the $2002-2019$ period. Total beds in non-system hospitals declined by $27 \%$ while beds in system hospitals increased $16 \%$. As a result, the percentage of total beds in hospitals that are part of multi-hospital systems (excluding Kaiser hospitals) grew to well over half of all California hospitals (from $45 \%$ to $57 \%$ ).

An important and unique feature of the hospital market in California is the substantial presence and role of the Kaiser Permanente HMO and Kaiser's largely self-contained system of hospitals. Figure 4 summarizes the total population enrolled in Kaiser and the number of hospitals in the Kaiser system between 2007-2019. Kaiser's enrolled population has grown 25\% (1.7 million) over the 12-year period (2007-2019), from 6.7 million to 8.4 million.

For comparison, during the same period, California's total population grew 9\% (3.2 million) from 36.5 million to 39.4 million. As such, Kaiser's increase in

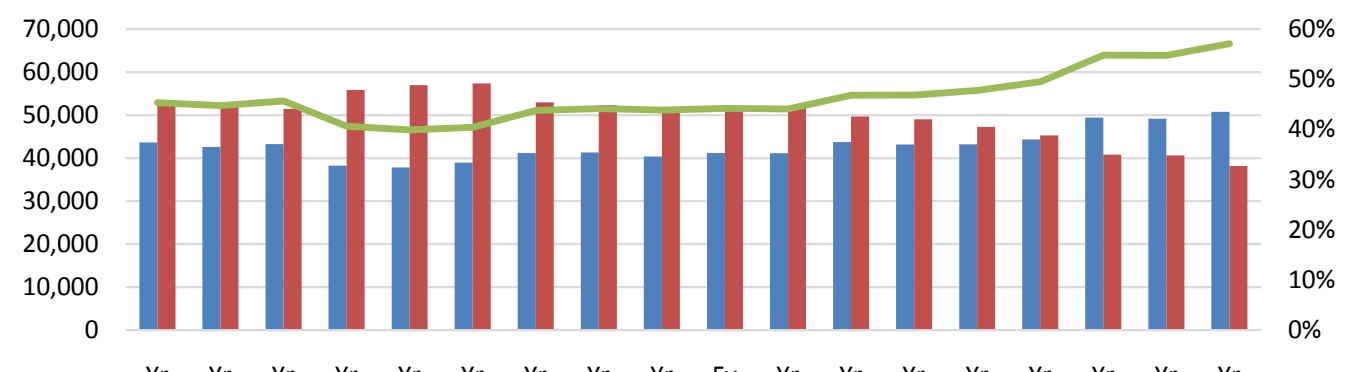

$\begin{array}{cccccccccccccccccc}Y r & Y r & Y r & Y r & Y r & Y r & Y r & Y r & \text { Yr } & \text { Fy } & \text { Yr } & \text { Yr } & \text { Yr } & \text { Yr } & \text { Yr } & \text { Yr } & \text { Yr } & \text { Yr } \\ 2002 & 2003 & 2004 & 2005 & 2006 & 2007 & 2008 & 2009 & 2010 & 2011 & 2012 & 2013 & 2014 & 2015 & 2016 & 2017 & 2018 & 2019\end{array}$

Beds - System Hospitals Beds - Non System Hospitals _—Percent Total Beds in System Hospitals

Figure 3. Supply of hospital beds by system status (excluding Kaiser system hospitals), California, 2002-2019.

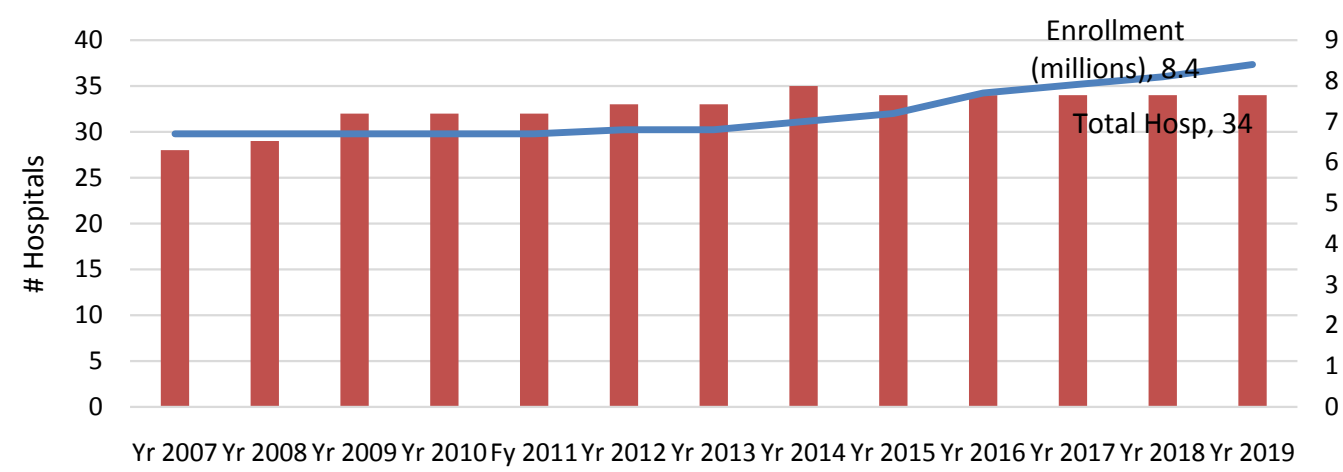

Figure 4. Kaiser hospital system: enrolled population and total acute care hospitals, 2007-2019. 
their enrolled population was slightly more than half of the overall growth in California's total population during the period. Unsurprisingly, Kaiser increased the number of hospitals in their system over the period by adding 6 hospitals for an expansion of $21 \%$. In contrast, and somewhat surprising, Kaiser reduced the total number of beds in their system hospitals by $-13 \%$ (from 5422 in 2007 to 4730 in 2019).

As described above, the total number of hospital systems in California has more than doubled from 14 to 30 between 2002 and 2019. Figure 5 summarizes changes in the size of systems (\# of member hospitals in the system) between 2002 and 2019 and Figure 6 reports the percentage of hospital beds in systems of different sizes between 2002 and 2019. As shown in Figure 5, the distribution of systems by size in terms of the number of member hospitals in the system has changed substantially. Now half of all systems are in the smallest category (5 hospitals or less) compared to $29 \%$ in 2002, while the percentage of systems in the largest size category ( 25 hospitals or more) has declined from $21 \%$ to just $7 \%$. The distribution of beds by system size follows a similar pattern where the larger systems have become a less dominant model and the smaller size systems are now playing a larger role in California's health care system. The percentage of beds in the largest systems in 2002 was well over half (55\%) but declined to $14 \%$ by 2019 , while systems with 10 or fewer hospitals now comprise more than half of all the beds (59\%) in multi-hospital systems in California.

Table 1 provides data on another important change in the nature of hospital systems in California over time-the clinical service focus and mix within each system. In 2002, all 14 of the systems in California were primarily focused on providing only a single service-acute care. By 2019, hospital systems had become more diverse in terms of their mix of services offered by system hospitals. Slightly more than half of the systems had a single service as their primary focus,

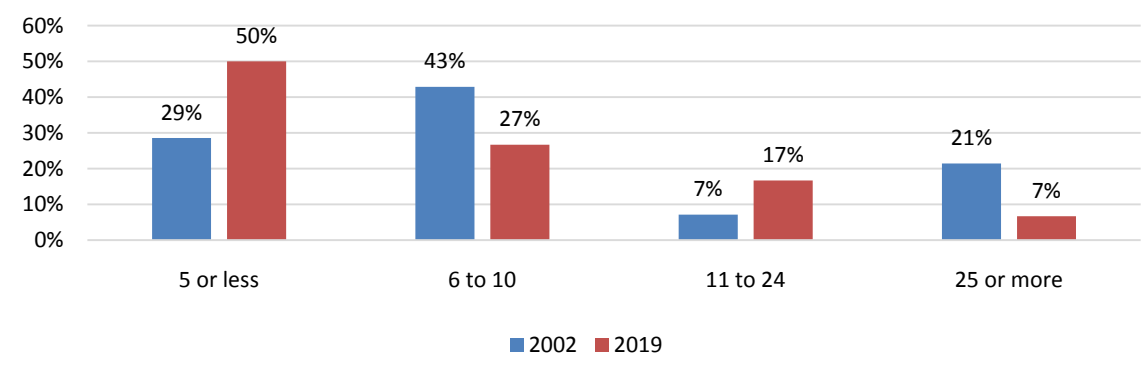

Figure 5. Percentage of hospital systems by system size (\# of member hospitals).

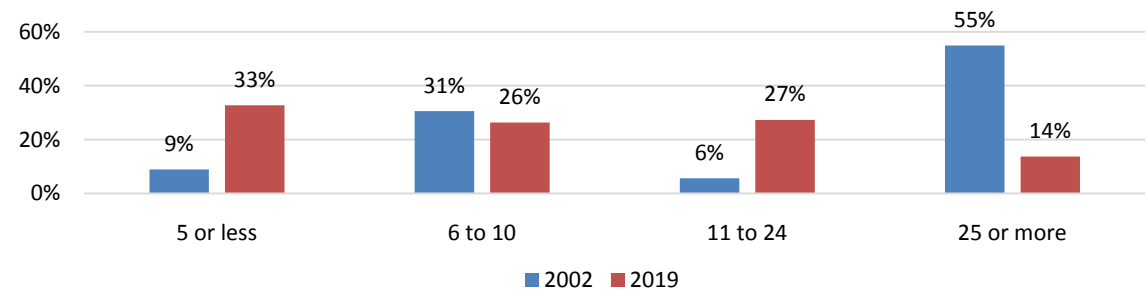

Figure 6. Percentage of hospital beds in systems by system size (\# of member hospitals) 
Table 1. Distribution of multi-hospital systems and system hospitals by service mix and ownership, 2019.

\begin{tabular}{cc}
\hline Service Mix & Number of Systems \\
\hline Acute & 12 \\
Psychiatric & 3 \\
Rehabilitation & 3 \\
Acute + Psychiatric & 5 \\
Acute + Long Term Care & 6 \\
Acute + Psychiatric + Long Term Care + Rehabilitation & 1 \\
Total & 30 \\
\hline
\end{tabular}

but now we see systems that focus not only on acute care $(\mathrm{n}=12)$ but also psychiatric care $(n=3)$ and rehabilitation services $(n=3)$. In addition, systems arose that provide multiple services including acute care as well psychiatric, rehabilitation and long-term care. Those systems with a non-acute care primary focus (psychiatric, rehabilitation) tend to be smaller in terms of bed size.

\section{Discussion and Conclusions}

Hospital consolidation into multi-hospital systems is gaining increasing media and regulatory attention. Our results show the increased role and potential impact of multi-hospital systems on the health care system. The number of multi-hospital systems in California more than doubled between 2002 and 2019 and now a majority of all hospitals are in a system (40\% to $60 \%$ of all hospitals, 2002 and 2019, respectively). The percentage of all hospital beds in California hospitals that are part of multi-hospital systems (excluding Kaiser hospitals) also grew, from $45 \%$ to $57 \%$ - suggesting that systems expanded by adding hospitals of average bed size, rather than adding many small hospitals or larger ones.

Importantly, the size distribution of multi-hospital systems in California changed substantially over time. In the early period, larger systems dominated the system landscape. Now, half of all systems have 5 or fewer hospitals compared to $29 \%$ in 2002 , while the percentage of systems with 25 or more members has declined from $21 \%$ to just $7 \%$.

The distribution of beds by system size follows a similar pattern where the larger systems have become a less dominant model and the smaller sized systems are now playing a larger role in California's health care system. As previously noted, the percentage of all system beds that was in large systems (25 or more hospitals) in 2002 was well over half (55\%) but declined to $15 \%$, almost switching places with smaller systems (10 or fewer members), which now contain more than half of all the beds in multi-hospital systems in California.

Another potentially important shift in the hospital system landscape is the apparent formation and growth of multi-hospital systems that offer a wider range or different mix of services than acute care only. In 2002, all 14 systems 
were largely acute care focused. By 2019, less than half of systems had acute care as their only and primary focus. Now, there are systems that focus on a single, non-acute service such as psychiatric care $(\mathrm{N}=3)$ or rehabilitation $(\mathrm{N}=3)$. There are other systems that continue to offer acute care services but also have large segments of their patients using services other than acute care.

The potential implications of these findings for future research are multiple. First, it appears that hospital systems are forming and evolving in a much more dynamic and varied way than is generally appreciated. Much of the attention and research to date has been on large systems and their potential to acquire market power, resulting in higher prices and lower quality and access. While there have been studies that examine all hospital systems as a group, to, for example study quality differences between system and non-system hospitals, they generally do not take into account the differences in the size of the systems or the service focus and mix of the systems.

More generally, the literature has yet to study in any great detail why there has been such a substantial increase in the number of small and medium size systems and the expanding clinical services of systems. For example, are there quality or efficiency benefits when standalone psychiatric hospitals join together into a single system? Or when they affiliate with acute care hospitals since an initial psychiatric episode may have started with an emergency visit to an acute care hospital? Another important aspect of multi-hospital systems formation and development that would benefit from further research is the geographic characteristics of systems and the location and proximity of system member hospitals. Again, for example, do smaller systems have more narrow geographic footprints than other systems, and, if so, what are the economic, quality, service and access implications of these models?

In sum, our results describe a rapidly growing and evolving multi-hospital system landscape that is more diverse than in the past. As such, further research is needed to better understand how these newly evolving systems are structured and whether there are now different kinds of models of multi-hospital systems depending on their service mix, size, geography and other factors (i.e., ownership, teaching status, other) that explain their performance. This understanding will contribute to development of effective public health policy and an evidence-based health care system.

\section{Acknowledgements}

We would like to acknowledge and thank the California Office of Statewide Health Planning and Development for providing the data for this paper. In addition, this work was supported in part by Arnold Ventures.

\section{Conflicts of Interest}

The authors declare no conflicts of interest regarding the publication of this paper. 


\section{References}

[1] MacDonald, I. (2017) Hospital Merger Mania Continues throughout the Country. https://www.fiercehealthcare.com/finance/hospital-merger-mania-continues-throug hout-country

[2] Flynn, A. and Knox, R. (2020) We're Short on Hospital Beds Because Washington Let Too Many Hospitals Merge. The Washington Post, 8 April 2020.

https://www.washingtonpost.com/outlook/2020/04/08/were-short-hospital-beds-be cause-washington-let-too-many-hospitals-merge/

[3] Prevost, T., Skillrud, I., Gerhardt, W. and Mukherjee, D. (2020) The Potential for Rapid Consolidation of Health Systems.

http://www2.deloitte.com/us/en/insights/industry/health-care/hospital-mergers-acq uisition-trends.html

[4] Creswell, J. and Abelson, R. (2013) New Laws and Rising Costs Create a Surge of Supersizing Hospitals. The New York Times, 12 August 2013.

http://www.nytimes.com/2013/08/13/business/bigger-hospitals-may-lead-to-biggerbills-for-patients.html?partner $=$ rss\&emc $=r s s \& \quad r=3 \&$

[5] Tsai, T.C. and Jha. A.K. (2014) Hospital Consolidation, Competition, and Quality: Is Bigger Necessarily Better? The Journal of the American Medical Association, 312, 29-30. http://jama.jamanetwork.com/article.aspx?articleid=1884584 https://doi.org/10.1001/jama.2014.4692

[6] Frakt, A. (2014) JAMA Forum: Hospital Consolidation Isn't the Key to Lowering Costs and Raising Quality.

http://newsatjama.jama.com/2014/11/11/jama-forum-hospital-consolidation-isnt-t he-key-to-lowering-costs-and-raising-quality/

[7] Davis, K.L. (2014) Hospital Mergers Can Lower Costs and Improve Medical Care: Stand-Alone Hospitals Have Too Few Patients to Thrive in the New Era of Population Health Management. Wall Street Journal, 15 September 2014.

http://www.wsj.com/articles/kenneth-l-davis-hospital-mergers-can-lower-costs-and -improve-medical-care-1410823048

[8] Lineen, J. (2014) Hospital Consolidation: 'Safety in Numbers' Strategy Prevails in Preparation for a Value-Based Marketplace. Journal of Healthcare Management, 59, 315-317. http://www.ache.org/pdf/secure/gifts/59 5 Lineen.pdf https://doi.org/10.1097/00115514-201409000-00003

[9] Wharton (2015) Hospital Consolidation: Can It Work This Time? Knowledge at Wharton University of Pennsylvania.

http://knowledge.wharton.upenn.edu/article/hospital-consolidation-can-it-work-thi s-time/

[10] Dafny, L. (2014) Hospital Industry Consolidation-Still More to Come? New England Journal of Medicine, 370, 198-199.

http://www.nejm.org/doi/full/10.1056/NEJMp1313948 https://doi.org/10.1056/NEJMp1313948

[11] Berenson, R.A., Ginsburg, P.B., Christianson, J.B. and Yee, T. (2012) The Growing Power of Some Providers to Win Steep Payment Increases from Insurers Suggests Policy Remedies May Be Needed. Health Affairs, 31, 973-981. 